\title{
Research \\ Low tissue oxygen saturation at the end of early goal-directed therapy is associated with worse outcome in critically ill patients
}

\author{
Alexandre Lima, Jasper van Bommel, Tim C Jansen, Can Ince and Jan Bakker
}

Department of Intensive Care, Room HS3.20, Erasmus MC University Medical Centre Rotterdam, PO Box 2040, 3000 CA Rotterdam, The Netherlands

Corresponding author: Prof. Jan Bakker, jan.bakker@erasmusmc.nl

Published: 30 November 2009

This article is online at http://ccforum.com/content/13/S5/S13

Critical Care 2009, 13(Suppl 5):S13 (doi:10.1186/cc8011)

(c) 2009 BioMed Central Ltd

\begin{abstract}
Introduction: The prognostic value of continuous monitoring of tissue oxygen saturation $\left(\mathrm{StO}_{2}\right)$ during early goal-directed therapy of critically ill patients has not been investigated. We conducted this prospective study to test the hypothesis that the persistence of low $\mathrm{StO}_{2}$ levels following intensive care admission is related to adverse outcome.

Methods: We followed 22 critically ill patients admitted with increased lactate levels $(>3 \mathrm{mmol} / \mathrm{l})$. Near-infrared spectroscopy (NIRS) was used to measure the thenar eminence $\mathrm{StO}_{2}$ and the rate of $\mathrm{StO}_{2}$ increase $\left(\mathrm{R}_{\text {inc }} \mathrm{StO}_{2}\right)$ after a vascular occlusion test. NIRS dynamic measurements were recorded at intensive care admission and each 2-hour interval during 8 hours of resuscitation. All repeated $\mathrm{StO}_{2}$ measurements were further compared with Sequential Organ Failure Assessment (SOFA), Acute Physiology and Chronic Health Evaluation (APACHE) II and hemodynamic physiological variables: heart rate $(\mathrm{HR})$, mean arterial pressure (MAP), central venous oxygen saturation $\left(\mathrm{ScvO}_{2}\right)$ and parameters of peripheral circulation (physical examination and peripheral flow index (PFI)).

Results: Twelve patients were admitted with low $\mathrm{StO}_{2}$ levels $\left(\mathrm{StO}_{2}\right.$ $<70 \%)$. The mean scores for SOFA and APACHE II scores were significantly higher in patients who persisted with low $\mathrm{StO}_{2}$ levels $(n=10)$ than in those who exhibited normal $\mathrm{StO}_{2}$ levels $(n=12)$ at 8 hours after the resuscitation period $(P<0.05$; median (interquartile range): SOFA, 8 (7 to 11 ) vs. 5 (3 to 8); APACHE II, 32 (24 to 33$)$ vs. 19 (15 to 25$)$ ). There was no significant relationship between $\mathrm{StO}_{2}$ and mean global hemodynamic variables (HR, $P=0.26$; MAP, $P=0.51$; $\mathrm{ScvO}_{2}, P=0.11$ ). However, there was a strong association between $\mathrm{StO}_{2}$ with clinical abnormalities of peripheral perfusion $(P=0.004), \mathrm{PFI}(P=0.005)$ and $\mathrm{R}_{\mathrm{inc}} \mathrm{StO}_{2}$ $(P=0.002)$. The persistence of low $\mathrm{StO}_{2}$ values was associated with a low percentage of lactate decrease $(P<0.05$; median (interquartile range): $33 \%$ (12 to $43 \%$ ) vs. $43 \%$ (30 to $54 \%)$ ).

Conclusions: We found that patients who consistently exhibited low $\mathrm{StO}_{2}$ levels following an initial resuscitation had significantly worse organ failure than did patients with normal $\mathrm{StO}_{2}$ values, and found that $\mathrm{StO}_{2}$ changes had no relationship with global hemodynamic variables.
\end{abstract}

\section{Introduction}

A more complete evaluation of tissue perfusion can be achieved by adding non-invasive assessment of peripheral perfusion to global parameters [1]. Non-invasive monitoring of peripheral perfusion is an alternative approach that allows very early application throughout the hospital, including the emergency department, operating room, and hospital wards. The rationale of monitoring peripheral perfusion is based on the concept that peripheral tissues are the first to reflect hypoperfusion in shock and the last to reperfuse during resuscitation $[1,2]$. Poor peripheral perfusion may therefore be considered an early predictor of tissue hypoperfusion and a warning signal of ongoing shock.

In the clinical practice, non-invasive monitoring of peripheral perfusion can be performed easily using current new technologies, such as near-infrared spectroscopy (NIRS) [3]. NIRS technology has been used as a tool to monitor tissue oxygen saturation $\left(\mathrm{StO}_{2}\right)$ in acutely ill patients [4]. In addition, the analysis of changes in $\mathrm{StO}_{2}$ during a vascular occlusion test, such as a brief episode of forearm ischemia, has been used as a marker of integrity of the microvasculature - in particular, the $\mathrm{StO}_{2}$ recovery after the vascular occlusion test [5-7]. These reports, however, have studied the correlation of intermittent $\mathrm{StO}_{2}$ measurements and outcome where there are only limited data describing whether continuous monitoring of $\mathrm{StO}_{2}$ during the early resuscitation phase is related to morbidity or to mortality.

We therefore conducted the present prospective observational study to investigate the association between continuous $\mathrm{StO}_{2}$ measurements during early resuscitation of high-risk patients and subsequent adverse outcomes. The primary study objective was to investigate whether persis-

$\mathrm{APACHE}=$ Acute Physiology and Chronic Health Evaluation; HR = heart rate; ICU $=$ intensive care unit; MAP = mean arterial pressure; NIRS = near-infrared spectroscopy; $\mathrm{PFI}=$ peripheral flow index; $\mathrm{R}_{\text {inc }} \mathrm{StO}_{2}=$ rate of tissue oxygen saturation increase; SOFA = Sequential Organ Failure Assessment; $\mathrm{StO}_{2}=$ tissue oxygen saturation; $\mathrm{ScvO}_{2}=$ central venous oxygen saturation. 
tence of low $\mathrm{StO}_{2}$ values during early goal-directed therapy could help to identify patients with more severe organ dysfunction and severity of disease as expressed by Sequential Organ Failure Assessment (SOFA) and Acute Physiology and Chronic Health Evaluation (APACHE) II scores. Because the value of $\mathrm{StO}_{2}$ as a parameter of peripheral perfusion is not quite clear, we also investigated the relation of low $\mathrm{StO}_{2}$ values with global hemodynamic and peripheral circulation parameters.

\section{Materials and methods Study population}

The current prospective observational study was conducted in the intensive care unit (ICU) of a university hospital. We enrolled 22 consecutive critically ill patients with increased lactate levels $(>3 \mathrm{mmol} / \mathrm{l})$ who had no history of severe peripheral vascular disease. The institutional review board approved the study. Each patient or relative provided written informed consent.

\section{Measurements}

Global hemodynamic variables included the heart rate $(H R)$, central venous pressure, mean arterial pressure (MAP) and central venous oxygen saturation $\left(\mathrm{ScvO}_{2}\right)$. All measurements were obtained using standard equipment. $\mathrm{ScvO}_{2}$ was measured continuously with a fiber-optic probe $\left(\mathrm{CeVOX}{ }^{\circledR}\right.$; Pulsion Medical Systems AG, Munich, Germany). Thenar $\mathrm{StO}_{2}$ was continuously monitored using an InSpectra Tissue Spectrometer Model 650 (Hutchinson Technology Inc., Hutchinson, MN, USA) with a $15 \mathrm{~mm}$ probe over the thenar eminence. Based on the variability of $\mathrm{StO}_{2}$ values in previous studies, we used a cut-off value of $70 \%$ to define the $\mathrm{StO}_{2}$ level as low [5-11].

We measured the $\mathrm{StO}_{2}$ response to the vascular occlusion test to investigate peripheral perfusion reactivity. The vascular occlusion test was performed using a sphygmomanometer cuff wrapped around the arm over the brachial artery. After a 1 -minute period to stabilize the NIRS signal, the cuff was rapidly inflated until $30 \mathrm{mmHg}$ above the systolic arterial pressure. After 3 minutes of ischemia, the sphygmomanometer was rapidly deflated and the $\mathrm{StO}_{2}$ was recorded until the $\mathrm{StO}_{2}$ level returned to baseline values. The vascular occlusion test-derived $\mathrm{StO}_{2}$ traces were analyzed for the rate of $\mathrm{StO}_{2}$ increase $\left(\mathrm{R}_{\mathrm{inc}} \mathrm{StO}_{2}\right)$ during the release. We calculated the $\mathrm{R}_{\text {inc }} \mathrm{StO}_{2}$ slope obtained by the regression line between the lowest $\mathrm{StO}_{2}$ value and the $\mathrm{StO}_{2}$ correspondent to the baseline value following the ischemic period (slope, expressed as percent per second). One individual who was blinded from all treatment and clinical data performed the NIRS measurements.

Peripheral circulation parameters included physical examination of peripheral perfusion and the peripheral flow index (PFI). Based on physical examination of peripheral perfusion, patients were considered to have abnormal peripheral perfusion if the examined extremities (both hands) had an increase in capillary refill time or were cool to the examiner's hands. The capillary refill time was measured by applying firm pressure to the distal phalanx of the index finger for 15 seconds. A chronometer recorded the time for the return of the normal color and 4.5 seconds was defined as the upper limit of normality [12]. The PFI provides a non-invasive method for evaluating perfusion and has been shown to reflect changes in peripheral perfusion [13,14]. The PFI is derived from the pulse oximetry signal, which was obtained from a Nellcor-OxiMax pulse oximeter and Hewlett Packard monitor (Viridia 56S, Philips Medical Systems, Boblingen, Germany).

The ICU contains single-person closed rooms, and the ambient temperature in each patient's room was individually and actively set at $22^{\circ} \mathrm{C}$.

\section{Study protocol}

All patients were followed during the first 8 hours after ICU admission. Hemodynamic support in all patients - including vasopressor (noradrenaline) and, if needed, addition of dobutamine - was aimed at standard resuscitation endpoints adapted from the Surviving Sepsis Campaign Guidelines to maintain $\mathrm{HR}<100 /$ minute, MAP $\geq 60 \mathrm{mmHg}$, central venous pressure of 8 to $12 \mathrm{mmHg}$, urinary output $\geq 0.5 \mathrm{ml} / \mathrm{kg} /$ hour and $\mathrm{ScvO}_{2} \geq 70 \%$ [15]. Measurements, obtained continuously between admission and the 8-hour period of resuscitation, included temperature, all global hemodynamic variables, $\mathrm{StO}_{2}$, the $\mathrm{PFI}$ and physical examination of peripheral perfusion. Arterial blood samples were withdrawn simultaneously for lactate measurement. The vascular occlusion test was performed at two time points: immediately upon admission to the ICU and again after 8 hours of resuscitation. Basic demographic characteristics, APACHE II and SOFA scores were collected for each patient. Clinical and laboratory data needed to calculate the SOFA and APACHE II scores were reported as the worst value within 24 hours after ICU admission.

Hyperlactatemia was defined as a blood lactate level $>3 \mathrm{mmol} / \mathrm{l}$. We calculated the percentage of lactate decrease over the first 8-hour period of ICU admission. All patients were mechanically ventilated and sedation with midazolam and analgesia was provided according to individual needs.

\section{Statistical analysis}

Unless otherwise specified, the results are presented as the median (interquartile range). Differences between group means were tested by Student $t$-tests; for variables that were not normally distributed, differences were tested by a nonparametric test. For clinical characteristics of the study groups, differences between groups were assessed using Fisher's exact test. The multiple regression analysis adjusted for global hemodynamic variables (HR, MAP and central venous pressure) was used to analyze the impact of the 
Table 1

\section{Patient demographic data}

Number of patients

Age (years)

Male/female

Sequential Organ Failure Assessment score

Acute Physiology and Chronic Health Evaluation II score

Admission category

Septic shock

Circulatory failure not associated with sepsis

Without circulatory failure or sepsis

Noradrenaline use

Noradrenaline dose $(\mu \mathrm{g} / \mathrm{kg} /$ minute)

Dobutamine use

Dobutamine dose $(\mu \mathrm{g} / \mathrm{kg} / \mathrm{minute})$

Mechanical ventilation

Survivor/nonsurvivor
22

62 (57 to 71$)$

$16 / 6$

7 (5 to 9$)$

23 (16 to 30$)$

3 pneumonia, 3 abdominal sepsis, 1 meningitis

3 hypovolemic/hemorrhagic, 3 cardiogenic, 4 postoperative, 2 trauma 1 cerebrovascular accident, 2 postoperative

$16(72 \%)$

$0.16(0.07$ to 0.24$)$

$8(36 \%)$

4.3 (3.6 to 6.3$)$

$15(68 \%)$

$17 / 5$

Data expressed as number, as median (25th to 75 th percentile), or as $n(\%)$.

persistence of $\mathrm{StO}_{2}<70 \%$ on the SOFA and APACHE II scores. We used the linear mixed-model analysis to assess the magnitude of contribution from each systemic and peripheral physiological variable on all repeated $\mathrm{StO}_{2}$ measurements during the 8 -hour period of resuscitation. $P \leq 0.05$ was considered statistically significant.

\section{Results}

Patients' demographic data are summarized in Table 1. All data used in the analysis were obtained at 2 hours, 4 hours, 6 hours and 8 hours after admission.

To explore the relationship between changes of $\mathrm{StO}_{2}$ and the severity of organ dysfunction, we stratified patients according to the evolution of $\mathrm{StO}_{2}$ levels within the 8-hour period of ICU resuscitation. Upon ICU admission, 12 (54\%) patients had low $\mathrm{StO}_{2}$ levels. From these 12 patients, two patients showed normalization of the $\mathrm{StO}_{2}$ levels. All patients admitted with normal $\mathrm{StO}_{2}$ still had a normal $\mathrm{StO}_{2}$ at 8 hours of resuscitation. A total of 10 patients therefore persisted with low $\mathrm{StO}_{2}$ and 12 patients with normal $\mathrm{StO}_{2}$ levels after the 8 hours of ICU resuscitation (Figure 1).

Figure 2 shows the SOFA and APACHE II scores stratified by the groups after 8 hours of resuscitation. The mean scores for both SOFA and APACHE II scores were significantly higher in patients who persisted with low $\mathrm{StO}_{2}$ levels than in those who exhibited normal $\mathrm{StO}_{2}$ levels 8 hours after the resuscitation period ( $P<0.05$; median (interquartile range): APACHE II score, 32 (24 to 33) vs. 19 (15 to 25); SOFA score, 8 (7 to 11$)$ vs. 5 (3 to 8$)$ ) (Figure 2). Multiple regression analysis on low $\mathrm{StO}_{2}$ levels adjusted for global hemodynamic variables (HR, MAP and central venous pressure) showed that low $\mathrm{StO}_{2}$ levels had a significant contribution for the prediction of SOFA score (regression coefficient $=3.0,95 \%$ confidence interval $=2.2$ to 5.7 ; $P=0.04$ ) and APACHE II score (regression coefficient $=9.1$, $95 \%$ confidence interval $=3.3$ to $13 ; P=0.026$ ).

The relationship between all repeated $\mathrm{StO}_{2}$ measurements during the 8-hour period of resuscitation with standard hemodynamic variables and with peripheral circulation parameters was assessed using the mixed-model analysis to further explore the contribution from each of these variables on the $\mathrm{StO}_{2}$ level. Table 2 presents the estimation coefficient from each variable. There was no significant relationship between $\mathrm{StO}_{2}$ and global hemodynamic variables. There was a strong association, however, between $\mathrm{StO}_{2}$ and clinical abnormalities of peripheral perfusion, the $\mathrm{PFI}$ and $\mathrm{R}_{\text {inc }} \mathrm{StO}_{2}$. Table 3 presents the descriptive analysis of global hemodynamic variables and peripheral circulation parameters stratified by the level of $\mathrm{StO}_{2}$ at admission and after 8 hours. In patients who received vasopressor therapy during resuscitation (number of patients $=16$; number of $\mathrm{StO}_{2}$ measurements $=$ $64)$, the dose of vasopressor (noradrenaline) did not differ between low $(n=35)$ and normal $(n=29) \mathrm{StO}_{2}$ levels ( $P=0.13$; median (interquartile range): 0.19 (0.10 to 0.33 ) vs. 0.13 (0.06 to 0.25$) \mu \mathrm{g} / \mathrm{kg} /$ minute).

Although there was no difference in admission lactate levels between patients with low and normal $\mathrm{StO}_{2}$ levels $(P=0.34$; median (interquartile range): 3.6 (2.2 to 6.0 ) vs. 3.4 (3.0 to 


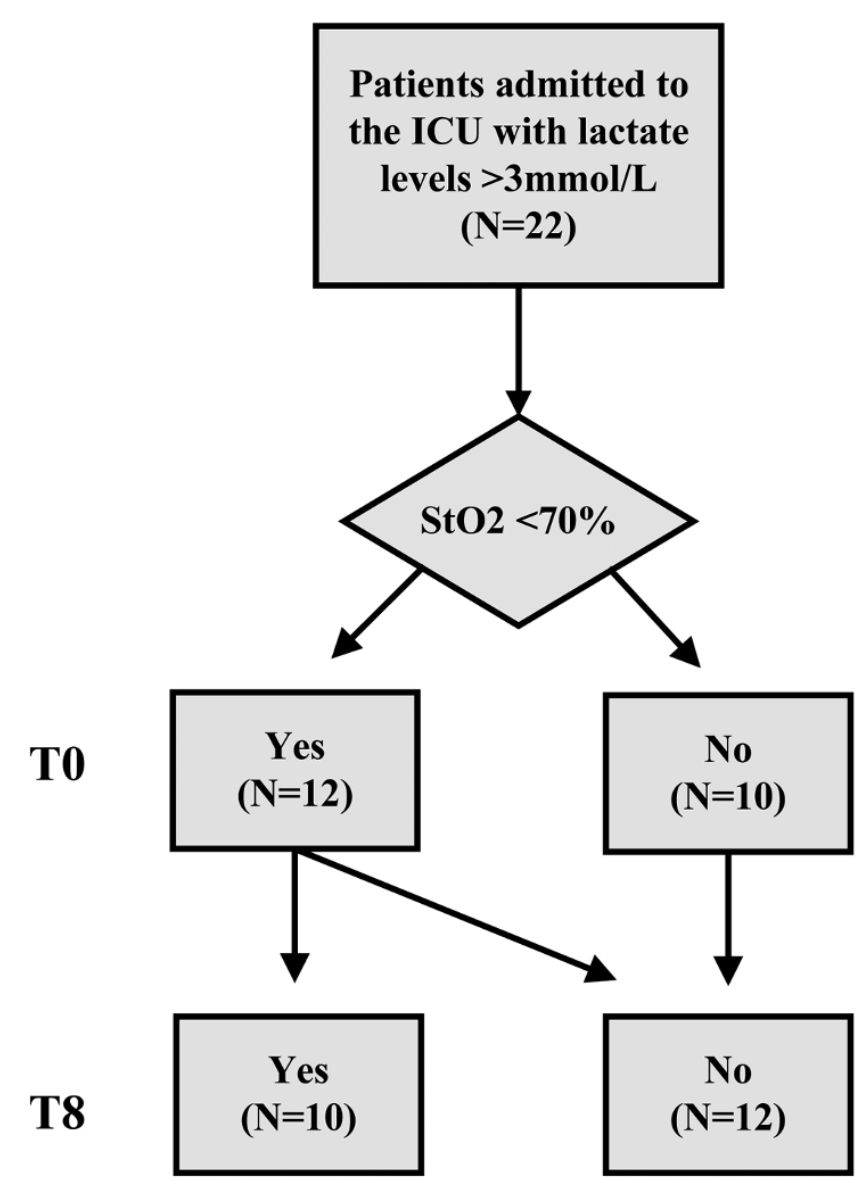

Evolution of $\mathrm{StO}_{2}$ levels in our patient population stratified by low $\left(\mathrm{StO}_{2}<70 \%\right)$ and normal $\left(\mathrm{StO}_{2} \geq 70 \%\right)$ values upon admission (TO) and $8 \mathrm{~h}$ after resuscitation (T8). ICU, intensive care unit; $\mathrm{StO}_{2}$, tissue oxygen saturation.

5.0)), the percentage of lactate decrease between admission and after the 8-hour period of resuscitation was significantly lower in patients who persisted with low $\mathrm{StO}_{2}$ levels $(P$ $<0.05$; median (interquartile range): $33 \%$ (12 to $43 \%$ ) vs. $43 \%$ (30 to 54\%)). A persistently low $\mathrm{StO}_{2}$ level was associated with increased mortality. Among the nonsurvivors, $4 / 5(80 \%)$ patients had persistently low $\mathrm{StO}_{2}$ levels after the 8-hour period of resuscitation - compared with 6/17 (35\%) patients in the survivor group.

\section{Discussion}

In the present prospective observational study, we performed repeated $\mathrm{StO}_{2}$ measurements in critically ill patients to test the hypothesis that the persistence of low $\mathrm{StO}_{2}$ levels during the early resuscitation phase of therapy is associated with a more severe organ dysfunction. The most important finding in our study is that patients who failed to normalize $\mathrm{StO}_{2}$ during early treatment in the ICU had more severe organ dysfunction and disease severity, as assessed by SOFA and APACHE ॥
Figure 2
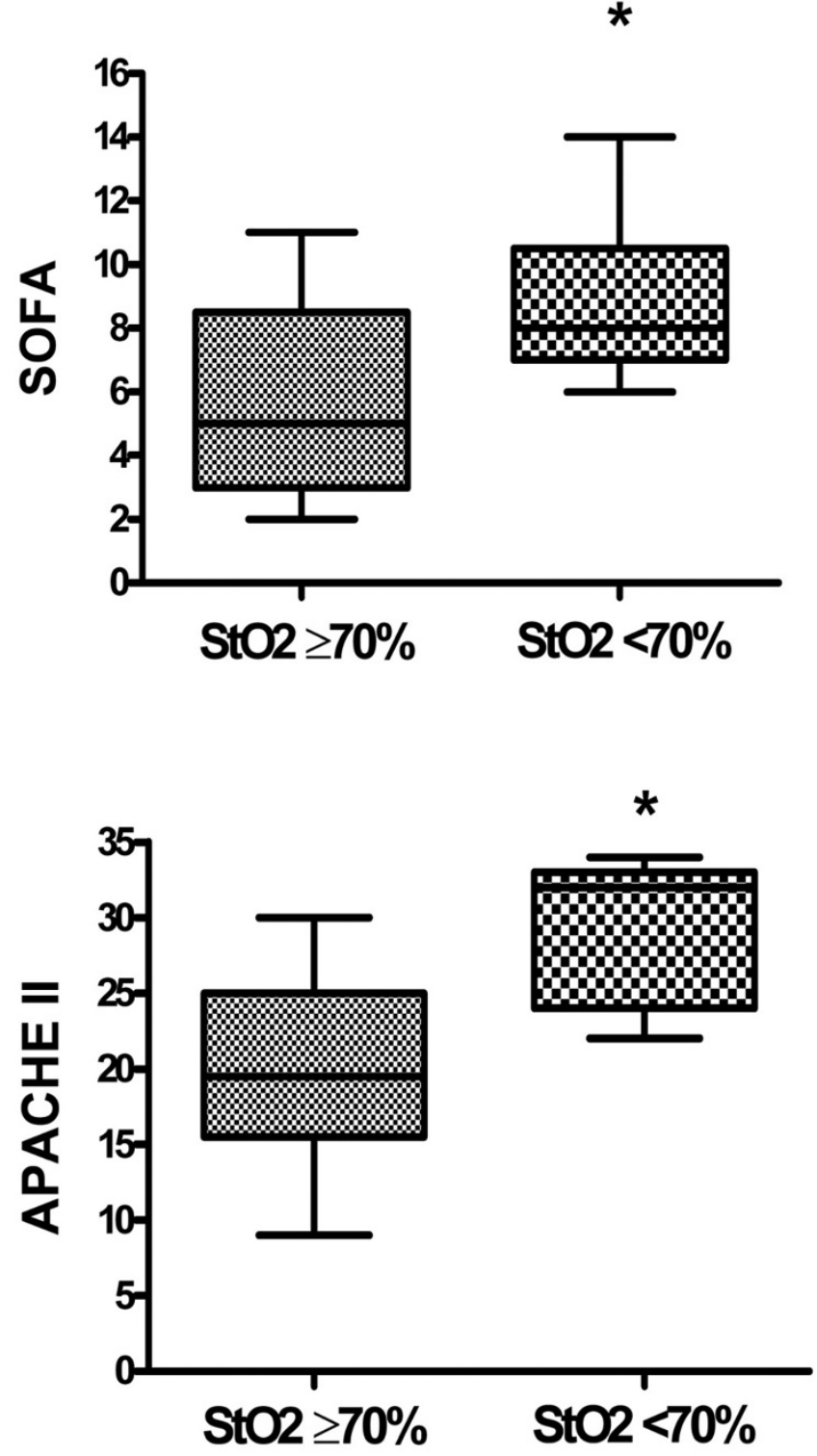

Box plotting demonstrating the outcome score values stratified by the $\mathrm{StO}_{2}$ levels $8 \mathrm{~h}$ after resuscitation: $\mathrm{StO}_{2}<70 \%(n=10) ; \mathrm{StO}_{2} \geq 70 \%$ $(n=12)$. APACHE, Acute Physiology and Chronic Health Evaluation; SOFA, Sequential Organ Failure Assessment; $\mathrm{StO}_{2}$, tissue oxygen saturation. *Significant, Wilcoxon rank test.

scores. The higher SOFA score in our patients with low $\mathrm{StO}_{2}$ levels could have been related to therapeutic interventions applied guided by global hemodynamic measurements. The association between low $\mathrm{StO}_{2}$ levels and organ failure in our patients, however, was not accompanied by any major differences in either global hemodynamic variables or doses of vasopressor therapy between patients with low and normal $\mathrm{StO}_{2}$ levels. In addition, we also found that the APACHE II score was significantly higher in patients with low $\mathrm{StO}_{2}$ 
Table 2

\begin{tabular}{|c|c|c|c|}
\hline$\underline{\text { Variable }}$ & $\mathrm{StO}_{2}$ estimation coefficient ( $95 \%$ confidence interval) & $P$-value & Number of observations \\
\hline \multicolumn{4}{|l|}{ Systemic hemodynamic } \\
\hline Heart rate & $-0.08(-0.23$ to 0.63$)$ & 0.26 & 88 \\
\hline Mean arterial pressure & $-0.05(-0.22$ to 0.11$)$ & 0.51 & 88 \\
\hline Central venous oxygen saturation & $0.11(-0.13$ to 0.36$)$ & 0.36 & 88 \\
\hline \multicolumn{4}{|l|}{ Peripheral circulation } \\
\hline Clinical abnormalities & 5.7 (2.0 to 9.6$)$ & 0.004 & 88 \\
\hline Peripheral flow index & $8.1(2.3$ to 13.1$)$ & 0.005 & 88 \\
\hline $\mathrm{R}_{\mathrm{inc}} \mathrm{StO}_{2}$ & $3.9(2.1$ to 6.0$)$ & 0.002 & 44 \\
\hline
\end{tabular}

Using the linear mixed-models analysis, we assessed the magnitude of contribution from each systemic and peripheral physiological variable on all repeated tissue oxygen saturation $\left(\mathrm{StO}_{2}\right)$ measurements during the 8-hour period of resuscitation. $\mathrm{R}_{\mathrm{inc}} \mathrm{StO}_{2}$, rate of $\mathrm{StO}$ increase after the vascular occlusion test.

Table 3

Global hemodynamic variables and peripheral circulation parameters stratified by $\mathrm{StO}_{2}$ level before and after resuscitation

\begin{tabular}{|c|c|c|c|c|c|c|}
\hline & \multicolumn{3}{|c|}{ Admission } & \multicolumn{3}{|c|}{ After 8 hours of resuscitation } \\
\hline & $\begin{array}{c}\text { Low } \mathrm{StO}_{2} \\
(n=12)\end{array}$ & $\begin{array}{c}\text { Normal } \mathrm{StO}_{2} \\
(n=10)\end{array}$ & $P$-value & $\begin{array}{c}\text { Low } \mathrm{StO}_{2} \\
(n=10)\end{array}$ & $\begin{array}{c}\text { Normal } \mathrm{StO}_{2} \\
(n=12)\end{array}$ & $P$-value \\
\hline Heart rate (beats/minute) & 94 (79 to 122$)$ & 91 (82 to 106$)$ & 0.90 & 95 (79 to 113$)$ & 98 (74 to 122$)$ & 0.90 \\
\hline Mean arterial blood pressure $(\mathrm{mmHg})$ & 77 (64 to 94$)$ & 79 (72 to 85$)$ & 0.87 & 67 (60 to 75$)$ & 72 (68 to 85$)$ & 0.14 \\
\hline Central venous pressure $(\mathrm{mmHg})$ & 15 (11 to 18$)$ & 12 (9 to 14$)$ & 0.20 & $19(6$ to 20$)$ & 15 (7 to 15$)$ & 0.34 \\
\hline Central venous oxygen saturation (\%) & 75 (63 to 79$)$ & 73 (68 to 84$)$ & 0.38 & 77 (68 to 85$)$ & $70(65$ to 80$)$ & 0.46 \\
\hline Peripheral flow index (\%) & $0.2(0.2$ to 0.7$)$ & 1.8 (0.8 to 3.7$)$ & 0.001 & $0.9(0.4$ to 1.1$)$ & 2.1 (1.2 to 3.0$)$ & 0.004 \\
\hline Clinical abnormalities of peripheral perfusion & $11(92 \%)$ & $3(30 \%)$ & $0.006^{\star}$ & $9(90 \%)$ & $1(8 \%)$ & $0.001^{*}$ \\
\hline $\mathrm{R}_{\mathrm{inc}} \mathrm{StO}_{2}(\% /$ second $)$ & $1.8(1.4$ to 2.0$)$ & $4.0(2.6$ to 4.7$)$ & 0.001 & 1.7 (1.2 to 2.5$)$ & 4.4 (2.9 to 4.7$)$ & 0.003 \\
\hline
\end{tabular}

Global hemodynamic variables and peripheral circulation parameters in patients with low tissue oxygen saturation $\left(\mathrm{StO}_{2} ;<70 \%\right)$ and normal $\mathrm{StO}_{2}$ $(>70 \%)$ at admission and after 8 hours of resuscitation. Data expressed as median (25th to 75 th percentile) or as $n(\%)$. $\mathrm{R}_{\mathrm{inc}} \mathrm{StO}_{2}$, rate of $\mathrm{StO} \mathrm{O}_{2}$ increase after the vascular occlusion test. *Significant, Fisher's exact test.

levels. The APACHE II score differs from the SOFA score since the former is not adjusted for the use of vasoactive drugs. These findings therefore suggest that the presence of low $\mathrm{StO}_{2}$ levels does not reflect global hemodynamic effects or vasoconstriction from a pharmacologic intervention.

The association between low $\mathrm{StO}_{2}$ levels and organ failure in our patients was accompanied by alterations in clinical abnormalities of peripheral perfusion. Current observations have shown a significant association between clinical abnormal peripheral perfusion and severity of organ dysfunction in patients suffering from either septic shock or nonseptic shock [16-19]. This relationship is supported by the present study. The association of low $\mathrm{StO}_{2}$ levels with clinical abnormalities of peripheral perfusion in our patients may partly explain the relationship between abnormal peripheral perfusion and a worse outcome. Additionally, low $\mathrm{StO}_{2}$ levels were also associated with a slow rise in $\mathrm{StO}_{2}$ following a vascular occlusion test. Abnormal $\mathrm{R}_{\text {inc }} \mathrm{StO}_{2}$ levels have been shown to reflect a variety of dynamic variables linked to local metabolic demand and vascular reactivity that have been associated with outcome in critically ill patients [5-7]. A causal relationship between low $\mathrm{StO}_{2}$ and abnormal $\mathrm{R}_{\text {inc }} \mathrm{StO}_{2}$ in our patients is not clear, as it was not the topic of the current study. Furthermore, the association between an abnormal $\mathrm{R}_{\mathrm{inc}} \mathrm{StO}_{2}$ and low $\mathrm{StO}_{2}$ levels is not always present, as previous reports have shown a decreased $\mathrm{R}_{\mathrm{inc}} \mathrm{StO}_{2}$ in the presence of normal $\mathrm{StO}_{2}$ values $[5,6]$. In our patients, however, an abnormal $\mathrm{R}_{\mathrm{inc}} \mathrm{StO}_{2}$ and low $\mathrm{StO}_{2}$ values were associated with a low $\mathrm{PFI}$, indicating either peripheral 
vasoconstriction and/or impairment of microcirculatory flow as indicated by the slowed reperfusion during ischemic recovery [20].

Although there was no difference in admission lactate levels, the percentage of lactate decrease during the study was significantly lower in patients who consistently exhibited low $\mathrm{StO}_{2}$ values. The interpretation of hyperlactatemia in critically ill patients is complex, and factors other than hypoperfusion may be involved [21]. Both hyperlactatemia at admission and the lack of its reduction during ICU treatment have been related to increased mortality [22-24]. The correlation between hyperlactatemia and low $\mathrm{StO}_{2}$ in our patients could be related to the presence of tissue hypoperfusion $[22,25,26]$. Nevertheless, our findings support previous reports, including our own, showing that patients with clinically abnormal peripheral perfusion following resuscitation are more likely to remain hyperlactatemic $[19,27]$.

Regardless of the cause of peripheral tissue hypoperfusion, our data provide evidence that the persistence of low $\mathrm{StO}_{2}$ values could have implications for the treatment of critically ill patients. Restoration of global hemodynamic parameters without an associated normalization of $\mathrm{StO}_{2}$ may warrant further or intensified resuscitation efforts. As the thenar muscle $\mathrm{StO}_{2}$ monitoring is safe, non-invasive and easily obtained at the bedside - enabling the physicians to identify patients with peripheral tissue hypoperfusion - it may represent a valuable addition to our monitoring tools and endpoints of goal-directed therapy. The clinical value of repeated $\mathrm{StO}_{2}$ measurements must be investigated further, however, to assess whether a resuscitation goal of normalizing $\mathrm{StO}_{2}$ levels will improve patient outcome.

The present study has some limitations that should be acknowledged. First, previous studies have suggested that resting $\mathrm{StO}_{2}$ values are insensitive indicators of tissue perfusion [5-7]. These studies noted that both patients and healthy control individuals had similar $\mathrm{StO}_{2}$ levels despite evidence of impaired systemic oxygenation in patients. In these studies, however, a $\mathrm{StO}_{2}$ threshold as well as a time factor was not taken into account. In our study, the repeated measurements of $\mathrm{StO}_{2}$ during early resuscitation were the prognostic factor, and the persistence of $\mathrm{StO}_{2}$ levels below the threshold of $70 \%$ was associated with the development of a more severe organ injury. Although the optimal $\mathrm{StO}_{2}$ threshold has not been fully investigated and not yet determined in critically ill patients, we arbitrarily chose $70 \%$ based on previous studies performed in healthy volunteers and in emergency and intensive care patients [5-11].

Second, the number of patients included in the present study was limited. Only two patients changed their $\mathrm{StO}_{2}$ level from low to normal; therefore, the prognostic value in this particular group could not be studied. From our findings, however, it is clear that patients who consistently showed low $\mathrm{StO}_{2}$ values within the first 8 hours of ICU treatment had a significantly higher rate of unfavorable outcome. Additionally, the absence of low $\mathrm{StO}_{2}$ levels identified patients with a more favorable outcome.

Finally, measurements of global blood flow (cardiac output) were not made in this study. Our main focus, however, was to assess the relationship between the presence of a low $\mathrm{StO}_{2}$ level following our standard hemodynamic optimization protocol and organ dysfunction.

In conclusion, we established the usefulness of the continuous monitoring of $\mathrm{StO}_{2}$ during the early resuscitation of critically ill patients. We found that patients who retained low $\mathrm{StO}_{2}$ levels following an initial resuscitation had significantly worse organ failure than did patients with normal $\mathrm{StO}_{2}$ values. In addition, low $\mathrm{StO}_{2}$ levels were only accompanied by alterations in the peripheral circulation - indicating that $\mathrm{StO}_{2}$ abnormalities are closely related to regional hemodynamics rather than macrohemodynamics.

\section{Competing interests}

The authors declare that they have no competing interests.

\section{Acknowledgements}

The present work was financially supported by department funds.

This article is part of Critical Care Volume 13 Supplement 5: Tissue oxygenation $\left(\mathrm{StO}_{2}\right)$ in healthy volunteers and critically-ill patients. The full contents of the supplement are available online at http://ccforum. $\mathrm{com} /$ supplements/13/S5. Publication of the supplement has been supported with funding from Hutchinson Technology Inc.

\section{References}

1. Chien LC, Lu KJ, Wo CC, Shoemaker WC: Hemodynamic patterns preceding circulatory deterioration and death after trauma. J Trauma 2007, 62:928-932.

2. Poeze M, Solberg BC, Greve JW, Ramsay G: Monitoring global volume-related hemodynamic or regional variables after initial resuscitation: what is a better predictor of outcome in critically ill septic patients? Crit Care Med 2005, 33:2494-2500.

3. Lima A, Bakker J: Noninvasive monitoring of peripheral perfusion. Intensive Care Med 2005, 31:1316-1326.

4. Creteur J: Muscle $\mathrm{StO}_{2}$ in critically ill patients. Curr Opin Crit Care 2008, 14:361-366.

5. Creteur J, Carollo T, Soldati G, Buchele G, De Backer D, Vincent $\mathrm{JL}$ : The prognostic value of muscle $\mathrm{StO}_{2}$ in septic patients. Intensive Care Med 2007, 33:1549-1556.

6. Gomez H, Torres A, Polanco P, Kim HK, Zenker S, Puyana JC, Pinsky MR: Use of non-invasive NIRS during a vascular occlusion test to assess dynamic tissue $\mathrm{O}_{2}$ saturation response. Intensive Care Med 2008, 34:1600-1607.

7. Skarda DE, Mulier KE, Myers DE, Taylor JH, Beilman GJ: Dynamic near-infrared spectroscopy measurements in patients with severe sepsis. Shock 2007, 27:348-353.

8. Taylor DE, Simonson SG: Use of near-infrared spectroscopy to monitor tissue oxygenation. New Horiz 1996, 4:420-425.

9. McKinley BA, Marvin RG, Cocanour CS, Moore FA: Tissue hemoglobin $\mathrm{O}_{2}$ saturation during resuscitation of traumatic shock monitored using near infrared spectrometry. J Trauma 2000, 48:637-642.

10. Ikossi DG, Knudson MM, Morabito DJ, Cohen MJ, Wan JJ, Khaw L, Stewart CJ, Hemphill C, Manley GT: Continuous muscle tissue oxygenation in critically injured patients: a prospective observational study. J Trauma 2006, 61:780-788.

11. Cohn SM, Nathens AB, Moore FA, Rhee P, Puyana JC, Moore EE, Beilman GJ: Tissue oxygen saturation predicts the develop- 
ment of organ dysfunction during traumatic shock resuscitation. J Trauma 2007, 62:44-54.

12. Schriger DL, Baraff L: Defining normal capillary refill: variation with age, sex, and temperature. Ann Emerg Med 1988, 17:932935.

13. Lima AP, Beelen $\mathrm{P}$, Bakker J: Use of a peripheral perfusion index derived from the pulse oximetry signal as a noninvasive indicator of perfusion. Crit Care Med 2002, 30:1210-1213.

14. Galvin EM, Niehof S, Verbrugge SJ, Maissan I, Jahn A, Klein J, van Bommel J: Peripheral flow index is a reliable and early indicator of regional block success. Anesth Analg 2006, 103:239243.

15. Dellinger RP, Levy MM, Carlet JM, Bion J, Parker MM, Jaeschke R, Reinhart K, Angus DC, Brun-Buisson C, Beale R, Calandra T, Dhainaut JF, Gerlach H, Harvey M, Marini JJ, Marshall J, Ranieri M, Ramsay G, Sevransky J, Thompson BT, Townsend S, Vender JS, Zimmerman JL, Vincent JL: Surviving Sepsis Campaign: international guidelines for management of severe sepsis and septic shock: 2008. Crit Care Med 2008, 36:296-327.

16. Hasdai D, Holmes DR, Jr, Califf RM, Thompson TD, Hochman JS, Pfisterer M, Topol EJ: Cardiogenic shock complicating acute myocardial infarction: predictors of death. GUSTO Investigators. Global utilization of streptokinase and tissue-plasminogen activator for occluded coronary arteries. Am Heart J 1999, 138:21-31

17. Thompson MJ, Ninis N, Perera R, Mayon-White R, Phillips C, Bailey L, Harnden A, Mant D, Levin M: Clinical recognition of meningococcal disease in children and adolescents. The Lancet 2006, 367:397-403.

18. Evans JA, May J, Ansong D, Antwi S, Asafo-Adjei E, Nguah SB, Osei-Kwakye K, Akoto AO, Ofori AO, Sambian D, Sylverken J, Busch W, Timmann C, Agbenyega T, Horstmann RD: Capillary refill time as an independent prognostic indicator in severe and complicated malaria. J Pediatr 2006, 149:676-681.

19. Lima A, Jansen T, van Bommel J, Ince C, Bakker J: The prognostic value of the subjective assessment of peripheral perfusion in critically ill patients. Crit Care Med 2008, 37:934-938.

20. Lima A, Ince C, Bakker J: Use of tissue oxygenation saturation in association with skin temperature as an indicator of the peripheral tissue perfusion in critically ill patients [abstract]. Crit Care 2009, 13:s236.

21. Bakker J: Lactate: may I have your votes please? Intensive Care Med 2001, 27:6-11.

22. Bakker J, Gris P, Coffernils M, Kahn RJ, Vincent JL: Serial blood lactate levels can predict the development of multiple organ failure following septic shock. Am J Surg 1996, 171:221-226.

23. Nguyen HB, Rivers EP, Knoblich BP, Jacobsen G, Muzzin A Ressler JA, Tomlanovich MC: Early lactate clearance is associated with improved outcome in severe sepsis and septic shock. Crit Care Med 2004, 32:1637-1642.

24. Smith I, Kumar P, Molloy S, Rhodes A, Newman PJ, Grounds RM, Bennett ED: Base excess and lactate as prognostic indicators for patients admitted to intensive care. Intensive Care Med 2001, 27:74-83.

25. Roumen RM, Redl H, Schlag G, Sandtner W, Koller W, Goris RJ: Scoring systems and blood lactate concentrations in relation to the development of adult respiratory distress syndrome and multiple organ failure in severely traumatized patients. J Trauma 1993, 35:349-355.

26. Durham RM, Moran JJ, Mazuski JE, Shapiro MJ, Baue AE, Flint LM: Multiple organ failure in trauma patients. J Trauma 2003, 55: 608-616.

27. Kaplan LJ, McPartland K, Santora TA, Trooskin SZ: Start with a subjective assessment of skin temperature to identify hypoperfusion in intensive care unit patients. J Trauma 2001, 50: 620-627. 